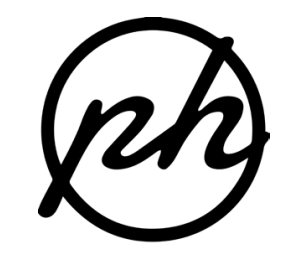

ESTUDIOS LINGÜÍSTICOS

\title{
LA DESFONOLOGIZACIÓN DE LAS VIBRANTES EN EL JUDEOESPAÑOL CONTEMPORÁNEO DE ISRAEL
}

\author{
DEFONOLOGIZATION BETWEEN FLAP AND TRILL IN CONTEMPORARY JUDEO- \\ SPANISH OF ISRAEL
}

\author{
Cristóbal José Álvarez López \\ Universidad Pablo de Olavide \\ cjalvarez@upo.es \\ ORCID: oooo-ooo3-1824-2641
}

Recibido: 22-10-2018

Aceptado: 14-12-2018

Publicado: 22-02-2019

\section{RESUMEN}

Entre los estudiosos, la oposición fonológica entre la vibrante simple / / / y la vibrante múltiple $/ \mathrm{r} /$ es un tema controvertido. Teniendo en cuenta solo los textos escritos -donde rara vez aparecía una resh doble-, no es sencillo establecer si en el desarrollo histórico del judeoespañol se mantuvo esta oposición fonológica o si se dio un proceso de desfonologización en la lengua sefardí.

Este artículo se centra en la descripción de la situación actual en lo que respecta a la desfonologización de las vibrantes en el judeoespañol contemporáneo de Israel. Para llevar a cabo mi análisis, tomo en consideración tanto textos escritos como orales. Por una parte, describo el uso del dígrafo <rr> en Aki Yerushalayim, una revista publicada en Israel desde 1979 hasta 2016 que se ha convertido en una referencia global del judeoespañol contemporáneo. Por otra parte, también analizo las realizaciones acústicas de la vibrante múltiple a través de varios espectrogramas extraídos de grabaciones orales de entrevistas a hablantes sefardíes que pude llevar a cabo durante una estancia de investigación en Israel.

Palabras clave:Judeoespañol, fonética, vibrante simple y vibrante múltiple, Aki Yerushalayim, entrevistas orales.

\section{ABSTRACT}

Among scholars, phonological opposition between flap / $\mathrm{r} /$ and trill / $\mathrm{r} / \mathrm{in}$ Judeo-Spanish is an issue. Considering just written text -where double resh hardly ever appeared-, it is not easy to establish whether the historical development of Judeo-Spanish kept this phonological opposition or a process of defonologization took place in the Sephardic language. 
This paper focuses on describing the current situation about defonologization between flap and trill in contemporary Judeo-Spanish of Israel. To perform my analysis, I take in account written and oral texts. On the one hand, I describe the use of the digraph $<$ rr $>$ in Aki Yerushalayim, a magazine published in Israel from 1979 to 2016 that has become a global reference of the contemporary Judeo-Spanish. On the other hand, I analyse the acoustic performance of the trill phoneme through several spectrograms taken from recorded oral interviews to Sephardic speakers that I could carry out during a research stay in Israel.

Keywords: Judeo-Spanish, phonetics, flap and trill, Aki Yerushalayim, oral interviews.

\section{Presentación}

La tradición gráfica del judeoespañol oriental -que durante siglos empleó la aljamía hebraica como sistema de escritura de sus textos- empleaba la grafía resh $<>>$ para representar, indistintamente, la vibrante simple / ₹/ y la vibrante múltiple /r/. El uso del dígrafo en palabras como טייררה (tierra) se comienza a documentar en los textos aljamiados entre finales del siglo XIX y principios del XX, si bien Bunis (1974:48, n. 31) atribuye este empleo a la influencia de ciertas ortografías extranjeras, especialmente a la francesa y la italiana. Así pues, a la hora de analizar, desde el punto de vista diacrónico, la evolución del sistema fonético y fonológico del judeoespañol, la indistinción gráfica de lo que podría ser dos fonemas distintos o un solo fonema -que tal vez pueda tener más de una realización alofónicacomplica muchísimo el análisis de la oposición entre vibrantes en judeoespañol. Además, la relación que se da entre la lengua hablada y la lengua escrita ha llevado, incluso, a postular la influencia de lo escrito en el proceso de desfonologización de las vibrantes:

Así, la sistemática grafía con res simple, en cualquier posición e independientemente de su valor etimológico, consecuencia directa de una restricción del sistema gráfico hebreo, pudo contribuir a la desaparición de la oposición entre la vibrante simple y la múltiple entre los sefardíes orientales. En cambio, en el Norte de África, donde apenas hubo desarrollo de la literatura escrita, y, por consiguiente, no llegó a imponerse ninguna norma gráfica, se mantuvo la oposición entre las dos vibrantes (Lleal 1993:116).

La oposición entre las vibrantes en el judeoespañol de Oriente es un tema que presenta bastante discrepancia entre los especialistas. Por eso, dedicaré el apartado siguiente a hacer un breve estado de la cuestión acerca del mantenimiento o no de la oposición entre la vibrante simpley la vibrante múltiple entre los sefardíes orientales. Tras la semblanza sobre los estudios previos, me detendré en el objetivo principal de este artículo: analizar la desfonologización de las vibrantes en el judeoespañol contemporáneo de Israel. Para llevar a cabo este estudio, me voy a servir de textos

1 En efecto, para el ejemplo anteriormente citado en aljamía, tanto el francés terre como el italiano terra emplean el dígrafo $<\mathrm{rr}>$ en su ortografía, a pesar de que tengan valores fonéticos diferentes. 
tanto escritos como orales del judeoespañol contemporáneo de Israel. Como fuente escrita, me voy a servir de los números de la revista Aki Yerushalayim, publicada en Jerusalén desde 1979 hasta 2016, en tanto que constituye uno de los principales referentes de las letras sefardíes contemporáneas por su enorme contribución a la revitalización de la lengua y por la influencia que ha ejercido en publicaciones posteriores, como el periódico ElAmaneser, de Estambul, que se publica desde 2005 siguiendo el sistema gráfico en caracteres latinos propuesto por Aki Yerushalayim. Y respecto a los textos orales, voy a emplear como fuente la docena de entrevistas que pude realizar en 2014 -gracias a una estancia de investigación en la Universidad Hebrea de Jerusalén- a informantes sefardíes residentes en Israel.

\section{BREVE ESTADO DE LA CUESTIÓN}

La bibliografía especializada presenta discrepancias a la hora de establecer si se mantiene en judeoespañol la oposición entre la vibrante simple / / / y la vibrante múltiple /r/ o si, por el contario, se ha producido a lo largo de su evolución histórica un proceso de neutralización y desfonologización, en favor de la vibrante simple / $\mathrm{f}$. Algunos autores han llegado afirmar tajantemente que no existe tal oposición entre vibrantes: «No variety of Judeo-Spanish distinguishes the vibrant /r/ from the flap /ґ/» (Penny 2000: 179); mientras que otros, como Ariza (2005: 397), constatan sus dudas acerca de «si existe o no en el judeoespañol la vibrante múltiple /r/», a partir del tratamiento dispar que hacen las fuentes escritas -y los estudiosos que las citan y transcriben en caracteres latinos- en lo que respecta a la distinción de las vibrantes. En todo caso, al hablar del proceso de desfonologización de las vibrantes en judeoespañol hay que tener presente que, como decía Sala (1970:129), se trata de una oposición con escaso rendimiento funcional que solamente es distintiva en contexto intervocálico y, por eso, la pérdida de la oposición entre estos dos fonemas «se puede interpretar como una simplificación del sistema fonológico por la eliminación de la oposición aislada dentro del sistema fonológico español» (Sala 1976: 539).

En mi opinión, la desfonologización de las vibrantes en judeoespañol es un fenómeno del que no es posible hablar en términos generales, puesto que además de la variación diacrónica que ha experimentado la lengua sefardí en sus más de cinco siglos de historia, también hay que tener en cuenta que el judeoespañol estaba disperso por diversos territorios de la cuenca del Mediterráneo, de ahí que la conservación o pérdida de la oposición no se diera por igual en todas las zonas. A este respecto, resultan especialmente esclarecedores los estudios de Quintana Rodríguez, ya que la autora establece una isoglosa² que divide las áreas geográficas

2 En el epígrafe dedicado a la «Desfonologización de /r/» (Quintana Rodríguez 20o6: 8488), además de establecer la isoglosa que divide las diferentes áreas dialectales del judeoespañol en relación con esta característica fónica, también se hace un breve estado de la cuestión -de recomendada lectura- acerca de cuál es la opinión al respecto de algunos de los más destacados investigadores del judeoespañol. 
donde se conserva la distinción entre la vibrante simple / / / y la vibrante múltiple /r/, frente a las zonas en que dicha oposición está neutralizada:

El sistema de las consonantes empleado en el judeoespañol de las comunidades de Grecia, Macedonia, Turquía, Israel y Egipto posee dos consonantes alveolares vibrantes, /r/ y / / /. La primera se realiza con vibraciones múltiples, y la segunda con una vibración simple. [...]

En el sistema de las consonantes del judeoespañol empleado en las comunidades de Bosnia, Serbia, Croacia, Bulgaria y Rumanía la antigua oposición intervocálica /-r-/ : /-ז-/ se neutralizó, con lo cual se produjo la desfonologización del primer fonema (Quintana Rodríguez 2006: 84).

Así pues, según esta isoglosa, en los textos orales y escritos del judeoespañol de Israel cabría esperar, en principio, que se diera la distinción entre las dos vibrantes. Ahora bien, esta oposición se mantuvo estable hasta comienzos del siglo pasado: «Durante las primeras décadas del siglo Xx se mantenía claramente la oposición $/ \mathrm{r} /$ : / $/$ en las comunidades de Grecia, Macedonia, Turquía e Israel» (Quintana Rodríguez 2006: 87). Sin embargo, con los diversos movimientos migratorios propiciados por las distintas guerras que tuvieron lugar en estos territorios en la primera mitad del siglo -comenzando por las Guerras Balcánicas y terminando por la II Guerra Mundial-, las fronteras lingüísticas experimentaron cambios significativos, de manera que las antiguas isoglosas vigentes a comienzos del siglo no quedaron tan definidas después de estos conflictos bélicos y, en lo que concierne a las vibrantes, en la actualidad ya no se mantiene la separación previa en áreas dialectales:

En los últimos años, también en el judeoespañol de las comunidades del sur se observa el mismo proceso innovador que se venía desarrollando desde un siglo antes en las comunidades del interior y que, sin duda, desembocará en la neutralización de la oposición /-r-/ : /-؟-/ (Quintana Rodríguez 2006: 87-88).

Por tanto, la desfonologización de las vibrantes en el judeoespañol oriental es un «proceso innovador» que ha ido ganando terreno a lo largo del siglo xx, propiciado, como ya se ha dicho, por el escaso valor fonológico que tiene la oposición de estos dos fonemas.

Una vez hechas estas puntualizaciones, es el momento de pasar al análisis de textos escritos y orales del judeoespañol contemporáneo de Israel para ver en qué medida son válidos estos planteamientos acerca de la desfonologización de las vibrantes.

\section{LA OPOSICIÓN ENTRE VIBRANTES EN LA REVISTA AKI YERUSHALAYIM}

Para analizar la oposición entre vibrantes en el judeoespañol contemporáneo escrito me voy a basar en los textos de la revista Aki Yerushalayim, publicada en Jerusalén desde1979 hasta 2016. Enlos cien números que editó esta revista durante sus 
37 años de existencia hay numerosos artículos, reportajes, entrevistas, pasatiempos, reseñas de libros y discos, textos literarios de diferentes épocas y lugares, etc., todo escrito íntegramente en judeoespañol. De hecho, entre los objetivos de la revista, además de la difusión de los contenidos culturares y folclóricos relacionados con el mundo sefardí, estaba también el fomento de la producción escrita en judeoespañol, como se manifiesta abiertamente en la revista3:

1- Azer mijor konoser la kultura i el folklor de los Djudios Sefaradis (de orijin Espanyola) ansi ke sus istoria i sus estado aktual.

2- Estimular i ayudar a renovar en la mizura del posible, la aktividad literaria i folklorika en Djudeo-Espanyol (AY, 2:6 [1980], anteportada).

Esta breve declaración de intenciones, tomada del número 6, de julio de 1980, aparece con ligeras modificaciones hasta el último número. En ella se puede comprobarla importancia que, junto a la difusión cultural, sele concedía a la creación de textos en judeoespañol y, por ello, Aki Yerushalayim contribuyó al fomento de la producción literaria en lengua sefardí ( $c f$. Shaul 2007). De ahí el interés por tomar esta publicación como referente del judeoespañol contemporáneo escrito de Israel.

Asimismo, en lo que respecta a las grafías, hay que señalar que desde el primer número el equipo de redacción propone un sistema de escritura en caracteres latinos -recuérdese que la tradición gráfica sefardí era la escritura aljamiada, si bien desde finales del siglo XIX se comenzaron a emplear cada vez más las grafías latinas para el judeoespañol ${ }^{4}$ - con la idea de homogeneizar la producción escrita en judeoespañol, puesto que, como se afirmaba en la revista, «kaje i no ay dos personas ke eskrivan de la mizma manera» (AY, 1:1 [1979], 3). La propuesta de la revista se plasma en un texto publicado en el número 1, de abril de 1979, bajo el título «Es ke ay menester de una nueva ortografia para el djudeo-espaniol?» (AY, 1:1 [1979], 3-4). En esta propuesta inicial hay un total de 27 elementos gráficos -la versión última contiene $3^{1-}$, entre los cuales no se encuentra el dígrafo $<$ rr $>$. La tabla de grafías de la revista va cambiando a lo largo de los diversos números5, pero habrá que esperar hasta el número 5o, de 1994, para ver el dígrafo <rr> incluido -tras 15 años de publicación- entre los demás elementos gráficos del judeoespañol de la revista, en una nueva versión de la tabla de grafías, más completa que las anteriores -que solo incluían algunos elementos que podrían plantear ciertos problemas

3 Las citas extraídas de Aki Yerushalayim siguen el siguiente formato: (AY, año:número [fecha de publicación], página).

4 La primera publicación periódica en emplear las grafías latinas fue El Luzero de la Pasensia (Turnu Severin, Rumanía, 1885-1888): «[...] El Luzero se proclama orgulloso de ser la única publicación periódica "en skritura i lingoa spaniola" del ámbito sefardí oriental, presentando el uso del alfabeto latino -o, lo que es lo mismo, el abandono de la tradicional grafía aljamiada- como un avance hacia la occidentalización de los sefardíes orientales, que los hará más competitivos en el mundo moderno: "eso les será con el tiempo una grande utilidad para el negocio, que ataran grandes relaciones entre el Oriente y la Europa" (año III, núm. 16, pág. 217)» (Díaz-Mas y Barquín 2007: 38).

5 Sobre la evolución de la propuesta gráfica de Aki Yerushalayim, véase Álvarez López (2017: 82-87). 
de lectura- donde se ofrecen las equivalencias de las grafías de Aki Yerushalayim con el IPA -International Phonetic Alphabet, según sus siglas en inglés, o AFI en español- y con las que emplean el «Diksionario Nehama», «Şalom» $\mathrm{y}$ «Vidas Largas» (AY, 15:50 [1994], 1). De nuevo, esta tabla experimentó ligeros cambios en la nomenclatura de los apartados -además de que en el número 51, de 1995, se añadió una nueva columna dedicada a las «Letras Rashi» (AY, 16:51 [1995], 3)-, hasta que finalmente, tras suprimir las equivalencias en otros sistemas gráficos del judeoespañol e incorporar las vocales a la tabla, en el número 6o, de mayo de 1999, apareció por primera vez la tabla de grafías definitiva, que se mantuvo ya sin cambios hasta el fin de la publicación en 2016 -a excepción del número 93, de abril de 2013, que presenta una tabla diferente con el nombre de las letras y ejemplos diferentes- y que contiene todos los elementos gráficos empleados por la revista:

GRAFIA DEL DJUDEO-ESPANYOL

SIGUN EL METODO DE

AKI YERUSHALAYIM

\begin{tabular}{|c|c|c|c|}
\hline $\begin{array}{l}\text { ART } \\
\text { YERUSBALAYMM }\end{array}$ & IPA & Eashemplo & Prononsiasion \\
\hline A & $\mathrm{a}$ & amar & \\
\hline B & b & bueno & \\
\hline CH & t $\int$ & chiko & \\
\hline $\mathbf{D}$ & d & demandar & \\
\hline DJ & 女 & djudia & Komo "jumbo" en inglez \\
\hline $\mathbf{E}$ & e & este & \\
\hline $\mathbf{F}$ & $f$ & famiya & \\
\hline G & $g$ & gato & \\
\hline H & $\mathrm{x}$ & hazino & Komo "j" en espanyol: jefe, jardín, jabón \\
\hline H & $\mathrm{x}$ & es.huenyo & $\begin{array}{l}\text { Solo kuando el "h" viene despues un "s" } \\
\mathrm{i} \text { aun kon esto deve ser prononsado komo } \\
\text { "h" I no komo "sh": shavon, shabat, efc. }\end{array}$ \\
\hline 'H & h & 'Herzl & $\begin{array}{l}\text { Kuando deve prononsarse komo el "Hey" } \\
\text { ebreo }\end{array}$ \\
\hline $\mathbf{I}$ & $\mathbf{i}$ & venir & \\
\hline $\mathbf{J}$ & 3 & ojos & Komo uj" en transez: jour, journal, etc. \\
\hline $\mathbf{K}$ & k & kaza & $\begin{array}{l}\text { Komo "c" espanyola en "casa" o "qu" en } \\
\text { "que" }\end{array}$ \\
\hline ks & $k+s$ & aksion & Komo en espanyol en "acción o extra" \\
\hline $\mathbf{L}$ & I & Iana & \\
\hline $\mathbf{M}$ & $\mathrm{m}$ & meter & \\
\hline $\mathbf{N}$ & $n$ & no & \\
\hline NY & $\mathrm{n}$ & anyo & Komo en espanyol en "año, cuñado" \\
\hline 0 & o & oro & \\
\hline $\mathbf{P}$ & $p$ & poko & \\
\hline $\mathbf{R}$ & r & ora & \\
\hline RR & $\mathrm{rr}$ & serrar & \\
\hline $\mathbf{s}$ & s & paso & Komo en espanyol en "pasar o salvar" \\
\hline sH & $\int$ & shavon & $\begin{array}{l}\text { Komo "chic" en fransez, "short" en } \\
\text { inglez o la "Caixa" en katalan. }\end{array}$ \\
\hline $\mathbf{T}$ & $t$ & topar & \\
\hline $\mathbf{u}$ & $u$ & un, tu & \\
\hline $\mathbf{v}$ & $\beta$ & vaka & \\
\hline $\mathbf{x}$ & $g+z$ & examen & Solo komo en "examen o exekutir" \\
\hline $\mathbf{Y}$ & j & yo & \\
\hline $\mathbf{z}$ & $z$ & koza & Komo en franséz en "zéro, rose" \\
\hline
\end{tabular}

Los nombres de personas se eskriven sigun los uzan eskrivir las personas ke los yevan: Cohen, Coen o Koen; Levy o Levi, etc.

Los nombres de sivdades i paizes se eskriven komo en sus lengua, salvo los kavzos onde ya se formaron en djudeo-espanyol nombres o grafias diferentes.

Por enshemplo: Londra i no Londres o London; Estambol i no Istanbul, etc.

Tabla 1: Tabla con las grafías de la revista Aki Yerushalayim 
La consideración acerca de las vibrantes que plantea la revista Aki Yerushalayim resulta contradictoria. En el número 1, de abril de 1979, no aparece el dígrafo $<\mathrm{rr}>$ recogido en la tabla inicial de grafías, aunque se utiliza en varias ocasiones, en palabras como djarro, fierro, tierra, etc. Asimismo, se siguió empleando este dígrafo en todos y cada uno de los números de la revista, pero no aparece en la tabla de grafías hasta el número 50, de 1994 -«Numero espesial» que conmemoraba los 15 años de publicación-, y se mantiene hasta el final de la publicación, salvo el caso ya mencionado del número 93, de abril de 2013, donde desaparece ${ }^{6}$ el dígrafo $<$ rr $>$-puesto que solo aparece $<\mathrm{r}>$, bajo la denominación «Er»-, mientras que sí que aparecen otros dígrafos como $<$ ny $>$ y $<$ sh $>$, nombrados como «nye» $\mathrm{y}$ «SHe», respectivamente.

Por otra parte, a pesar de que en la tabla de grafías definitiva aparecen las vibrantes como dos fonemas diferentes 7 , es muy habitual encontrar vacilaciones entre $<\mathrm{r}>\mathrm{y}$ $<$ rr $>$. Conforme pasan los años de publicación se aprecia una mayor aparición de la grafía doble, pero nunca llega a ser sistemática. Algunas voces siempre aparecen con el dígrafo $<\mathrm{rr}>$, tales como enterramiento, irreparavle o perro; mientras que otras como gerra, korrer, marrano y tierra tienen una alta frecuencia de aparición con $<\mathrm{rr}>$, si bien es posible encontrar ejemplos dispersos de gera, korer, marano y tiera, con la grafía simple. Pero la tónica general en lo que se refiere a la escritura de las vibrantes es la constante alternancia entre voces escritas con $<\mathrm{r}\rangle$ o con $<\mathrm{rr}\rangle$, como puedan ser, por ejemplo, los pares arrankar/arankar, arivar/arrivar, derredor/deredor, serrar/ serar, etc. En parte, es cierto que se puede llegar a pensar que esta alternancia se debe a los distintos autores que firman las contribuciones a la revista -aunque el equipo de redacción de la revista, desde el número 7, de noviembre de 1980, llevó a cabo una tarea de homogeneización gráfica que podría haber eliminado tales vacilaciones, en caso de que se hubiera estimado oportuno para evitar confusiones entre los lectores ${ }^{8}-$, pero incluso se dan casos extremos como yerro/yero $(A Y, 1: 2$ [1979], 16), que alternan en la misma página de un mismo texto.

Sin embargo, a pesar de las alternancias, no he conseguido localizar ningún caso donde se emplee <rr > -hay que tener en consideración que su uso en los pares alternantes siempre suele ser inferior- en una palabra a la que etimológicamente le corresponda una vibrante simple. Si se hubieran dado confusiones de este tipo, se podría haber postulado la total neutralización y desfonologización de los dos fonemas, pero hay que tener presente que $<$ rr $>$ es un dígrafo que va apareciendo

\footnotetext{
6 La ausencia solo se da en la tabla de este número, puesto que en el siguiente se descarta y se vuelve a la tabla de grafías que venía usándose desde el número 6o, de mayo de 1999. Sin embargo, no deja de ser llamativa la omisión del dígrafo $<$ rr $>$-de nuevo, muestra de su escasa integración en el sistema-, frente a los demás dígrafos que sí aparecen represados.

7 Nótese que no es correcta la representación de las vibrantes de la tabla según el AFI, ya que figuran como /r/ y /rr/ y deberían aparecer como / $/ \mathrm{y} / \mathrm{r} /$, respectivamente.

8 «Visto la grande difikultad ke estamos teniendo a eskrivir los artikolos ke resivimos de afuera kon las grafías partikulares de sus autores, i en baza de letras ke resivimos i konversasiones ke tuvimos kon muestros lektores, desidimos ke la revista entera sera eskrita kon una sola grafía, konformamente al alfabeto ke vos prezentamos al empesijo de kada numero» $(A Y, 2: 7$ [1980], 6).
} 
cada vez más en la revista conforme avanzan los números y, seguramente, conforme aumenta el contacto gráfico de los redactores con otras lenguas que emplean los caracteres latinos, ya sea el español, o bien el inglés, el francés o el italiano. Por tanto, el dígrafo solo aparece en las voces que también se escriben con esa misma grafía en estas otras lenguas, con lo cual, más que reflejar una articulación distinta que permita hablar de dos fonemas, la aparición de $<$ rr $>$ se limita a recoger una tradición escrituraria previa.

\section{LA OPOSICIÓN ENTRE VIBRANTES EN FUENTES ORALES}

A finales de 2014, gracias a una estancia de investigación en la Universidad Hebrea de Jerusalén, tuve la oportunidad de entrevistarme con varios informantes sefardíes residentes en el Estado de Israel; es más, siete de las doce personas que pude entrevistar incluso habían nacido en Jerusalén, entre 1928 y 1944, antes de la fundación del Estado de Israel en 1948.

De los materiales sonoros que pude recopilar, para hacer una comparación más precisa, me voy a servir únicamente de la lectura que hicieron mis informantes de un texto publicado en la revista Aki Yerushalayim. En concreto, se trata de un fragmento de un cuento titulado «Aramban i su goral», aparecido en el número $5^{\circ}$, de 1994. De cara a realizar las grabaciones, les di el texto a los informantes para que pudieran realizar una primera lectura y se familiarizaran con el contenido, con el fin de que, durante la grabación, la lectura posterior fuera más fluida y espontánea -puesto que también quería analizar la entonación, aspecto prosódico que en este artículo no es pertinente-. Me he decidido a emplear esta parte de las entrevistas -que tiene una duración media de unos dos minutos- porque, a pesar de la inicial falta de naturalidad que tiene un texto que está siendo leído -de ahí la importancia de la lectura previa-, resulta muy interesante que sea el mismo texto para poder comparar mejor los resultados.

En lo que respecta a la vibrante múltiple, en el fragmento grabado solamente hay una palabra -serrados - a la que le corresponde etimológicamente este fonema en posición intervocálica ${ }^{9}$, como se aprecia en la oración en la que aparece: «Lo van a trayer delantre del Sultan i le van a meter una chanaka delantre de el, i arientro dos papeles serrados» $\left(A Y, 15: 5^{\circ}[1994], 95\right)$. Hay que destacar que en este cuento la palabra serrados aparece escrita con el dígrafo $<\mathrm{rr}>$, con lo cual cabría esperar que, en principio, la influencia de la escritura produjera que todos los informantes articularan una vibrante múltiple, aunque, claro está, para poder articularla no basta con el estímulo gráfico, sino que también es necesario que cuenten con ese fonema en su sistema fonológico.

9 Téngase en cuenta que, como se ha señalado anteriormente, la oposición entre vibrantes -de escaso rendimiento funcional (Sala 1970: 129) - solo es distintiva en contexto intervocálico. 
A continuación, sirviéndome del programa informático Praat ${ }^{10}$, voy a reproducir los espectrogramas correspondientes a algunas de las realizaciones que obtuve de mis informantes para la vibrante de la palabra serrados.

La primera informante que he seleccionado nació en Estambul en 1945 -reside en Israel desde 1949- y esta es su articulación de la palabra serrados:

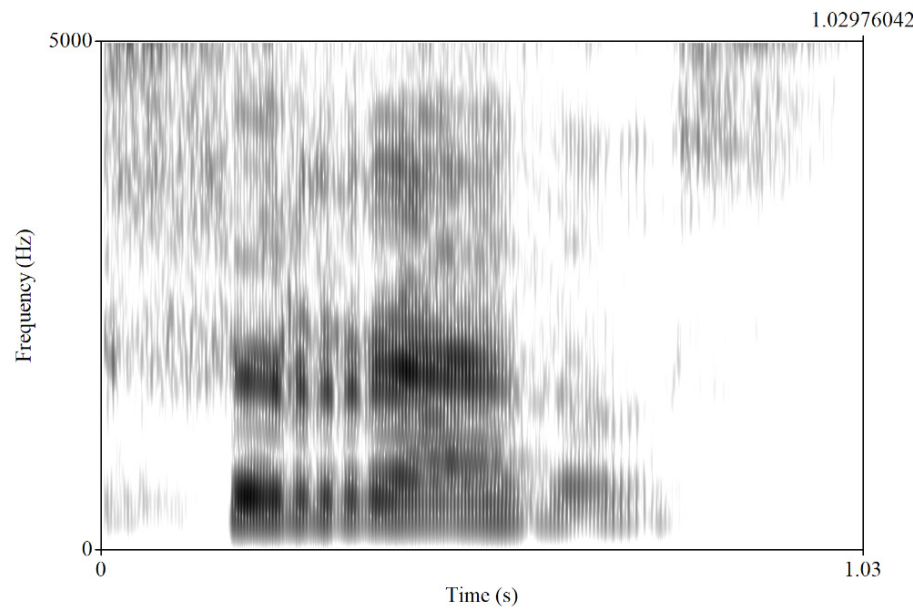

Figura 1: Espectrograma de la palabra serrados pronunciada por la informante 1

Se puede apreciar que el espectrograma muestra la articulación como vibrante múltiple de esta informante, ya que aparecen perfectamente marcadas las interrupciones de la salida del aire que caracteriza la realización de este fonema:

En cuanto a su caracterización acústica, en el espectrograma cada interrupción de la salida del aire se traduce en un espacio blanco a lo largo de todas las frecuencias, seguido de breves formantes insestables. Este blanco indica la breve oclusión en el caso de la vibrante simple, o las dos o tres oclusiones en el caso de la vibrante múltiple en el habla normal, aunque el número de oclusiones puede aumentar en pronunciación enfática (Hidalgo Navarro y Quilis Marín 2012: 209).

En concreto, en la realización de esta primera informante se pueden contabilizar un total de cuatro franjas en blanco, por lo que se trata, según la cita anterior, de una «pronunciación enfática», tal vez motivada por un esfuerzo articulatorio, en este caso.

He querido comenzar este análisis por la informante que con más claridad articula una vibrante múltiple pero, en líneas generales, se trata de lo menos frecuente entre las encuestas que pude realizar.

10 Es una aplicación de software libre para el análisis del habla que puede ser descargada desde su página web: <http://www.fon.hum.uva.nl/praat/>. 
Pasemos, a continuación, a un segundo informante, nacido en Esmirna en 1929 y residente en Israel desde 1949:

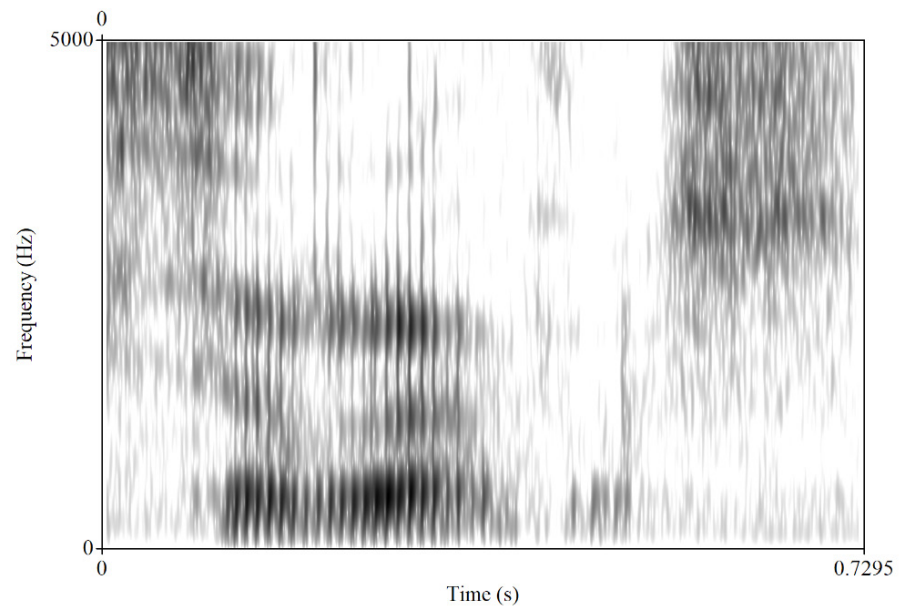

Figura 2: Espectrograma de la palabra serrados pronunciada por el informante 2

En este segundo espectrograma se aprecia que, entre los dos fonemas vocálicos -bien diferenciados por sus formantes-, se articula nuevamente una vibrante múltiple, si bien en esta ocasión ya no está tan clara desde el punto de vista acústico como la articulada por la informante que, como ya he indicado, era una excepción entre los casos registrados. A pesar de la falta de nitidez -acústica y, por tanto, gráfica en el espectrograma-, todavía en este segundo ejemplo es posible hablar de un mantenimiento de la vibrante múltiple, si bien con una articulación menos precisa.

Por otra parte, como señala Quintana Rodríguez (2006: 85), la desfonologización de $/ r /$ no es un fenómeno exclusivo del judeoespañol, sino que también en el mundo hispánico - por tratarse de una oposición de carácter marginal- es posible encontrar realizaciones asibiladas o velarizadas ${ }^{11}$.

En lo que respecta a la articulación asibilada, ya Navarro Tomás (2004 [1918]: 123124, § 117) hacía referencia a la pronunciación fricativa con asibilación de la vibrante, en un parágrafo dedicado a los «Defectos relativos a la $r r »$, como rasgo dialectal del español. Acústicamente, la vibrante asibilada no presenta las interrupciones propias de la vibrante múltiple, sino que se aprecia una zona fricación continua. Esto se puede observar en el espectrograma de la informante 3, nacida en Estambul en 1943 y residente en Israel desde 1965:

11 Estas realizaciones se documentan en amplias zonas de Hispanoamérica ( $c f$. Moreno de Alba 1988: 158-161). 


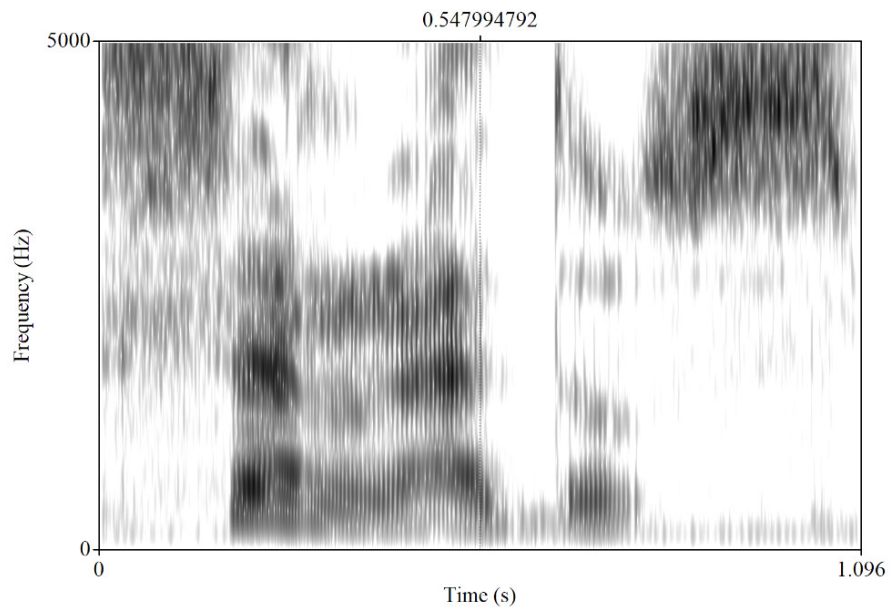

Figura 3: Espectrograma de la palabra serrados pronunciada por la informante 3

No hay, como se puede apreciar, ninguna interrupción en la articulación de la vibrante, a pesar de que el rasgo [+ interrupto] es básico en la definición acústica de las vibrantes pero, en este caso, se observa que la articulación es más próxima a una fricativa. Hay que señalar, asimismo, que la pronunciación asibilada que se recoge en el espectrograma anterior tiene una duración relativamente alta, frente a lo que se puede advertir en el ejemplo siguiente, de una informante nacida en Jerusalén en 1928:

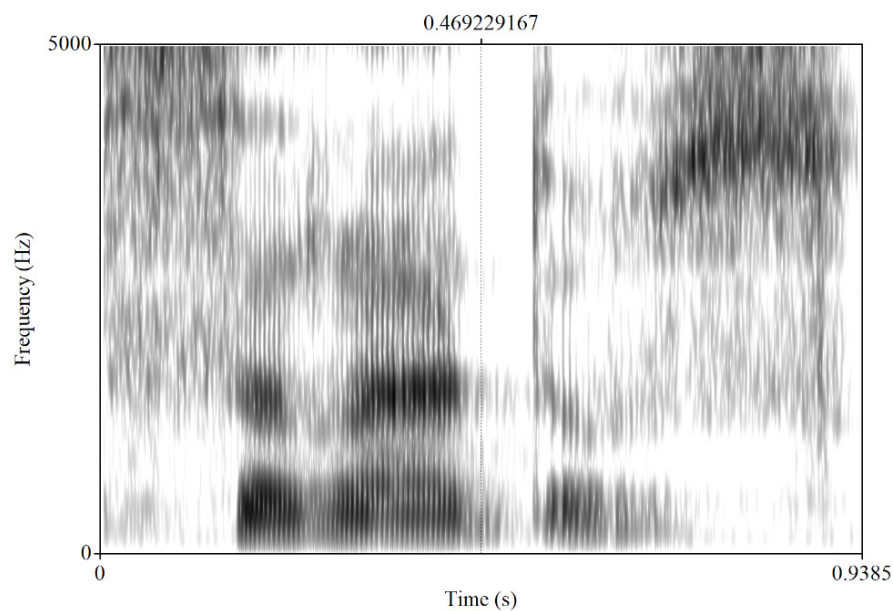

Figura 4: Espectrograma de la palabra serrados pronunciada por la informante 4 
En ambos casos -el de la informante 3 y el de la informante 4- se puede constatar la ausencia de interrupciones, pero hay que resaltar la diferencia en la duración entre ambas realizaciones, que tal vez pueda atribuirse a que la informante 3 tenía, al menos en su conciencia lingüística, la intención de articular una vibrante múltiple -de ahí la mayor duración, aunque no tenga interrupciones-, frente a la informante 4, que presenta una articulación con una duración inferior, más cercana a una vibrante simple asibilada.

Además de los casos de asibilación, también he podido constatar un ejemplo de velarizaciónque, comoyahe apuntado, tampoco es innovador entrelossefardíes, sino que también se constata en zonas de Hispanoamérica. En concreto, este fenómeno está localizado en América Central y se dan varias hipótesis acerca de su desarrollo, tales como la influencia de las lenguas africanas de los esclavos o la proliferación de lenguas criollas con base francesa u holandesa, por citar sucintamente algunas explicaciones de este fenómeno. Para el caso del judeoespañol contemporáneo de Israel esta articulación se puede atribuir a la influencia de la fricativa uvular sonora /в/ del hebreo. Esta realización velarizada es la que emplea el informante 5, nacido en Jerusalén en 1942:

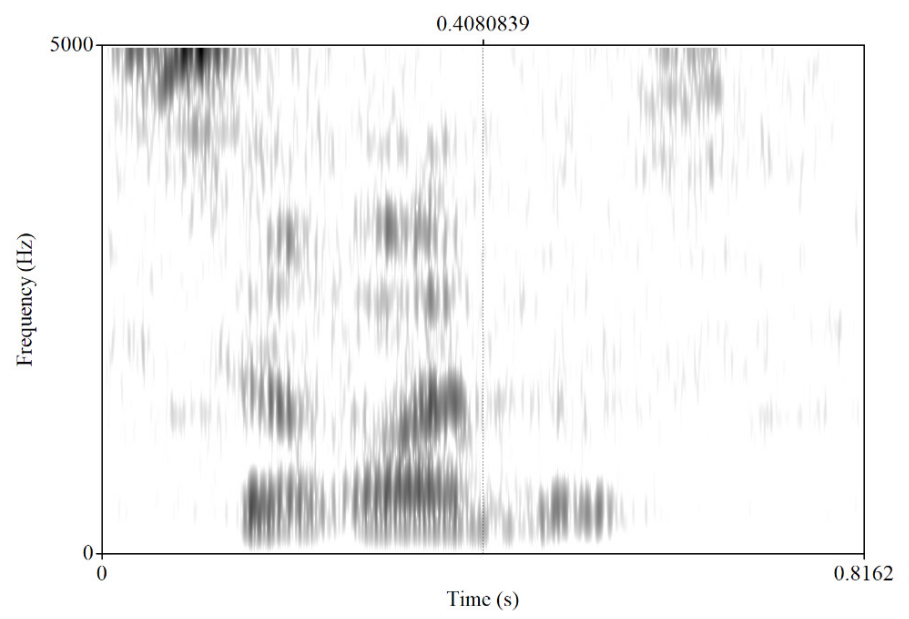

Figura 5: Espectrograma de la palabra serrados pronunciada por la informante 5

Finalmente, también es posible encontrar la realización de la palabra serrados como si se tratara de una vibrante simple, que desde el punto de vista acústico se manifiesta en el espectrograma con una sola interrupción, como se puede apreciar en la realización del informante 6, nacido en Sarajevo ${ }^{12}$ en 1969 y residente en Israel desde 1991:

\footnotetext{
12 Recuérdese que, según la isoglosa descrita por Quintana Rodríguez (2006: 84), Sarajevo se incluye en la zona de interior donde cabe esperar la desfonologización de las vibrantes en favor de la simple.
} 


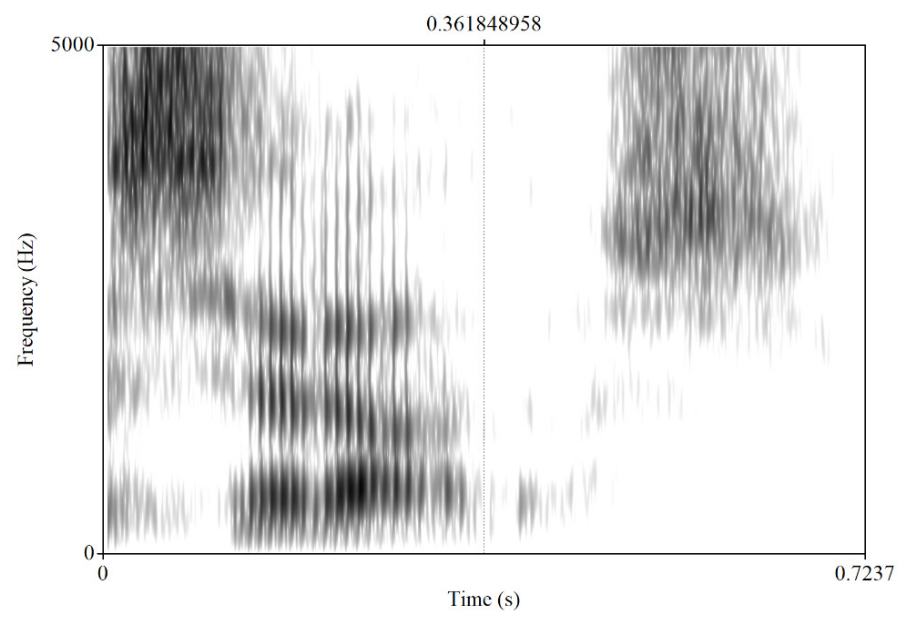

Figura 6: Espectrograma de la palabra serrados pronunciada por el informante 6

En resumen, de los doce informantes -solamente he representado aquí los espectrogramas de seis, por motivos de espacio, ya que los restantes apenas difieren de los que he ofrecido- que pude entrevistar en mi estancia en Israel, hay cuatro casos destacables: los informantes 1 y 2 son los que articulan una vibrante múltiple -si bien la informante 1 lo hace de manera enfática, mientras que el informante 2 no presenta una realización tan definida-; el informante 5 realiza una pronunciación velarizada, por influencia del hebreo; y el informante 6 articula la palabra serrados como si de una vibrante simple se tratara. El resto de informantes de la muestra que he manejado se mueve en un contínuum de difícil segmentación con realizaciones más o menos asibiladas y de mayor o menor duración, factor que habría que relacionar con el intento de mantener, junto a la asibilación, el carácter simple o múltiple de la consonante.

\section{Conclusiones}

En las páginas de este artículo se ha analizado la oposición entre la vibrante simple / / / y la vibrante múltiple /r/ en el judeoespañol contemporáneo de Israel.

Como punto de partida, hay que destacar que, según ya había señalado la bibliografía especializada, se trata de una oposición aislada de escasa rentabilidad en el sistema -estos dos fonemas solo se oponen en posición intervocálica y no son abundantes los pares mínimos que se diferencian por esta oposición- y de ahí que sea factible una simplificación, sobre todo teniendo en cuenta que ninguna de las lenguas con las que ha estado en contacto el judeoespañol en sus más de cinco siglos de historia tiene la vibrante múltiple, de modo que es un fonema que nunca se vio reforzado dentro del sistema fonológico sefardí a través de los préstamos. Además, como ya señaló Quintana Rodríguez, la desfonologización de /r/ era un fenómeno que 
establecía una isoglosa entre las comunidades del interior -donde los dos fonemas se habían neutralizado y desfonologizado-y las del sur -con el mantenimiento de la oposición-, donde se incluyen las comunidades más numerosas e influyentes, como son las de las ciudades de Salónica, Estambul y Esmirna.

Respecto al judeoespañol contemporáneo escrito, me he centrado en el tratamiento que hace la revista Aki Yerushalayim de las vibrantes. Por una parte, la inclusión del dígrafo $<$ rr $>$ en la tabla de grafías es muy tardía -frente a otros dígrafos como $<\mathrm{dj}>\mathrm{o}<\mathrm{sh}>$, que aparecen desde el comienzo y, por tanto, se puede deducir que son las representaciones gráficas de fonemas bien adaptados en judeoespañol, a diferencia de lo que ocurre con /r/- y, por otra parte, su empleo en los diversos textos es irregular y asistemático. Es cierto que conforme avanza la publicación cada vez se va utilizando con más frecuencia el dígrafo $<\mathrm{rr}>$, pero nunca se llega a dar una sistematización global y, asimismo, su uso parece estar más relacionado con la influencia ejercida por otras lenguas que lo emplean -hay que tener presente que muchos textos de la revista no son originales, sino traducciones de otras lenguas $y$, por ello, cabe esperar que se mantengan las grafías $<$ rr $>$ cuando se tiene un estímulo visual que propicia su conservación en el texto traducido-.

Como complemento al estudio gráfico, también me he detenido en el análisis de textos orales para describir desde el punto de vista acústico la articulación de la vibrante ¿múltiple? en posición intervocálica. A través de los espectrogramas de la palabra serrados pronunciada por diversos informantes -de orígenes diferentes, pero todos residentes en Israel- se ha podido constatar que la realización como vibrante múltiple es la más escasa, a pesar del estímulo gráfico que supone el dígrafo $<$ rr $>$ del texto que estaban leyendo los informantes, y que, en líneas generales, abundan las realizaciones asibiladas -también hay un caso de una articulación velarizada, por influencia del hebreo- en las que la mayor o menor duración parece corresponderse con un intento -poco logrado- de producir una vibrante múltiple, si bien las características acústicas analizadas mediante procedimientos informáticos revelan que, de forma casi general, no se producen las interrupciones propias de una vibrante múltiple.

A modo de resumen, a partir de los textos escritos y orales analizados en este artículo y teniendo en cuenta los estudios previos acerca de las vibrantes en la historia de la lengua sefardí, es posible afirmar que en el judeoespañol contemporáneo de Israel prácticamente no se conserva la oposición entre la vibrante simple $/ \mathrm{r} /$ y la vibrante múltiple $/ \mathrm{r} /$, si bien todavía es posible encontrar algunos usos etimologizantes del dígrafo $<$ rr $>-$ sobre todo por influencia de otras lenguas- así como articulaciones que desde el punto de vista acústico mantienen las interrupciones propias de una vibrante múltiple -aunque de manera enfática a veces-, si bien la tónica general es la articulación asibilada, que también convive con la realización velarizada y con la confluencia con la vibrante simple; de modo que, debido a tanta variedad de articulaciones posibles, todo apunta a un único 
fonema vibrante, / / /, que tiene diversas realizaciones alofónicas, en distribución libre o estilística, y que cada hablante articula sin que haya cambios de significación asociados al empleo de cada uno de los posibles alófonos.

\section{REFERENCIAS BIBLIOGRÁFICAS}

ÁlVAREz LóPEZ, Cristóbal José (2017): Estudio lingüístico del judeoespañol en la revista "Aki Yersuhalayim". Tesis doctoral. Sevilla: Universidad de Sevilla.

ARIzA, Manuel (2005): «Algunas notas de fonética y de léxico del judeoespañol», en: El español en el mundo: Anuario del Instituto Cervantes. Madrid: Instituto Cervantes/ Plaza \& Janés/Círculo de lectores, 385-403.

Bunis, David M. (1974): The Historical Development of Judezmo Orthography: A Brief Sketch. New York: YIVO Institute for Jewish Reserch.

DíAz-Mas, Paloma/BARQuín, Amelia (2007): «Relaciones entre la prensa española y la prensa sefardí a finales del siglo XIX: el caso de El Luzero de la Pasensia», en: Martín Asuero, Pablo/Gerson Şarhon, Karen (eds.): Ayer y hoy de la prensa en judeoespañol (= Cuadernos del Bósforo, VII). Estambul: Isis, 37-46.

Hidalgo Navarro, Antonio/Quilis Merín, Mercedes (2012): La voz del lenguaje: Fonética y fonología del español. Valencia: Tirant Humanidades.

LLEAL, Coloma (1993): Lleal, Coloma (1993): «El sefardí y la norma escrita», en: Ribera, Josep (ed.): Actes del Simposi Internacional sobre Cultura Sefardita. Barcelona: Facultat de Filologia - Secció d'Hebreu i Arameu, 107-117.

Moreno de Alba, José G. (1988): El español en América. México: Fondo de Cultura Económica.

NAVARro Tomás, Tomás (2004 [1918]): Manual de pronunciación española. Madrid: Consejo Superior de Investigaciones Científicas.

PENNY, Ralph (2000): Variation and change in Spanish. Cambridge: Cambridge University Press.

QuintANA RoDRÍGUEZ, Aldina (2006): Geografía lingüística del judeoespañol: estudio sincrónico y diacrónico. Bern: Peter Lang.

SALA, Marius (1970): Estudios sobre el judeoespañol de Bucarest. México: Universidad Nacional Autónoma de México.

SALA, Marius (1976): Sala, Marius (1976): «Innovaciones del fonetismo judeoespañol». Revista de dialectología y tradiciones populares 32, 537-549.

SHAUL, Moshe (2007): «Kontribusion de la revista Aki Yerushalayim al renovamiento de la kreasion literaria en ladino», en: Martín Asuero, Pablo/Gerson Şarhon, Karen (eds.): Ayer y hoy de la prensa en judeoespañol (= Cuadernos del Bósforo, viI). Estambul: Isis, 91-96. 
